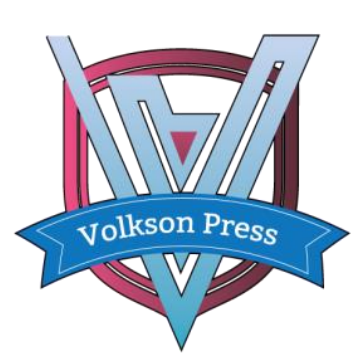

Contents List available at VOLKSON PRESS

Economics \& Management Innovations(EMI)

DOI : http://doi.org/10.26480/icemi.02.2018.44.47

ISBN: 978-1-948012-14-0

\title{
AN EMPIRICAL STUDY ON THE EFFICIENCY OF PRIVATE PLACEMENT FINANCING OF THE INFORMATION TRANSMISSION, SOFTWARE, AND INFORMATION TECHNOLOGY SERVICES INDUSTRY ABOUT THE NEW OVER THE COUNTER-— BASED ON THE DEA MODEL
}

\author{
Minjun Hu \\ School of Economics, Shanghai Univerisy, Baoshan district on the main road no. 99, Shanghai City, China. \\ *Corresponding Author Email: 1252141470@qq.com
}

This is an open access article distributed under the Creative Commons Attribution License, which permits unrestricted use, distribution, and reproduction in any medium, provided the original work is properly cited.

\section{ARTICLE DETAILS}

\section{Article History:}

Received 26 June 2018 Accepted 2 July 2018

Available online 1 August 2018

\begin{abstract}
The new OTC market has become a platform for corporate financing. Since the new OTC is an off-exchange market, the most important financing method for the listed companies is private placement. From the major funds flow the 2017 new OTC private placement, the most profitable industries are "Software and Services." This article uses data envelopment model (DEA) to analyze the efficiency of private placement financing of the information transmission, software, and information technology services industry about new over the counter market in China. The empirical results show that there are not many companies in the industry that achieve the best efficiency, and their financing efficiency is low, which is mainly because of various problems in the company itself. For example, scale efficiency is the main reason influencing the efficiency of financing. This article analyzes the reasons for the low financing efficiency from the variables of the sample companies and gives the optimization suggestions.
\end{abstract}

\section{KEYWORDS}

Private placement, DEA model, financing efficiency, technical efficiency, scale efficiency.

\section{INTRODUCTION}

The third board markets first originated from the 2001 "equity transfer system" and took over the two network companies and delisted companies, which are called "old three boards". As an important component of China's multi-level capital market, the new OTC market was originally designed to provide a platform for SME financing, broaden financing channels, and solved the financing difficulties of SMEs.

According to statistics of the small and medium-sized enterprises' share transfer system, there were 2,424 companies that had private placement and fund-raising activities in SMEs in the new OTC market in 2017, with a total of 128.413 billion yuan in private placement financing, accounting for $20.8 \%$ of the total number of new OTC enterprises. Among them, 205 companies have conducted two or more fund-raising activities, accounting for $8.5 \%$ of the number of fund-raising enterprises [1]. According to the Oriental Wealth Choice data, the industry distribution will increase in 2017 , and the software information industry accounts for $21.44 \%$ of the total, ranking the second only after the manufacturing industry. Information transmission, software and information technology services industries are the most profitable ones in terms of the amount of financing in 2017.

Private placement, also known as private placement, that is, issuing investment products such as stocks or bonds to investors, is relatively flexible in comparison with public additional methods, and is also the main financing method for listed companies in China's new OTC market. For SMEs with lower average valuation, more shares can be obtained through fixed increase, which can further strengthen the control of the company [2]. The impact on the concentration of shares will result in the transfer of interests of major shareholders. Therefore, the private placement financing method has both advantages and disadvantages.

Financing efficiency determines the daily production and operation activities of enterprises, and also determines the survival status and development prospects of enterprises in market competition. Most importantly, the financing efficiency of enterprises also affects the optimal allocation of the whole social resources. The basic definition of efficiency refers to the ratio of output to input, ie, the cost-to-benefit ratio. This article uses the DEA model to evaluate the decision-making units that analyze multiple inputs and multiple outputs, and obtain the comprehensive analysis results of financing efficiency, in order to analyze the reasons for the enterprises with low financing efficiency and to make recommendations.

\subsection{Literature Review}

The foreign research on financing efficiency has become more mature. As for the theory of SME financing, British MP Macmillan put forward the famous "Macmillan gap" theory in the 1930s, which found that there was a funding gap in the development process of SMEs. It is the earliest discussion of the financing gap [3]. There are several classic theories in the private placement activities: 1 . Hertzel, Richard's theory of information asymmetry. It is well known that the targeted private placement of listed companies is mainly composed of major shareholders and associated shareholders, institutional investors and other small and medium shareholders, so investors are bound to have the problems of information asymmetry. 2. On the basis of this, Hertzel put forward a monitoring theory, which pointed out that strengthening the control of corporate management's behavior can enhance the company's operating capability and produce a positive stock price effect. 3. In addition, Hertzel's research on the opportunity window theory shows that investors will choose the opportunity to choose investment, and listed companies will seize 
investors' optimistic view on the company's future development prospects and choose this opportunity for private placement. Moreover, there are also some foreign scholars who will study the efficiency of financing from the perspectives of the company's capital structure and the value of its value.

Domestic literature has started research on the market maker system and legal issues in the new OTC market since 2011. Research on the financing efficiency started in 2014, and there are abundant influential factors in the research on its financing efficiency in the past two years. For example, $\mathrm{Ni}$ Guangshun and Xu Xiangyang in 2009 used a fuzzy comprehensive evaluation method to analyze in detail the financing efficiency of the listed company Xiamen International Trade and concluded that its financing efficiency was poor. Chen Xianjin evaluated the efficiency of equity financing of companies listed on small and medium-sized boards in 2006 and concluded that equity financing efficiency of small and medium-sized listed companies in China needs to be further improved. Scholars at home and abroad based on different theories and perspectives analyzed in detail the factors influencing the efficiency of financing and put forward some suggestions [4].

\section{ANALYSIS OF FACTORS AFFECTING FINANCING OF INFORMATION TRANSMISSION, SOFTWARE AND INFORMATION TECHNOLOGY SERVICES IN THE NEW OTC MARKET}

According to the wind database statistics, the number of new OTC increased from 3 cases in 2007 to 3042 in 2016, and it decreased in 2017, with 2,725 private placement issues. However, overall, the number and number of private placements for the new OTC are still making rapid progress.

\subsection{External causes}

\subsubsection{Market reasons}

Market reason whether the growth rate of the level of economic development of the country's GDP is good or not, it will affect the entire economic market environment, thereby affecting the company's operating efficiency and profits, and finally influencing its financing efficiency.

\subsubsection{Policy system}

In recent years, China has introduced some policies to support small and medium-sized enterprises, especially for some high-tech small and medium-sized enterprises, by means of giving preferential policies such as subsidies. These orientations will also help companies to improve their financing costs and improve their financing efficiency.

\subsection{Internal reason}

\subsubsection{Enterprise scale}

The scale of the enterprise mainly includes total assets, operating income, and the number of employees. The larger the scale, the lower the financing cost and the higher the financing efficiency.

\subsubsection{Enterprise prospects}

If the company is in a growth period or has a better future prospects, such as high-tech industries, there will be more financing channels, and it will attract many investors with high financing efficiency.

\subsubsection{Corporate profitability}

That is the ability to obtain surplus value. It reflects in the financial index, including return on net assets and the main business growth rate. The higher the general profitability index, the better the financing efficiency.

\subsubsection{Concentration of ownership}

The more concentration of equity concentration, the company governance will prefer to the interests of shareholders first, which may reduce the operating capacity of the company and reduce its financing efficiency.

\section{EMPIRICAL RESEARCH}

\subsection{The establishment of DEA model}

Data Envelopment Model (DEA) is an efficiency evaluation method proposed by well-known American operational researcher Charnes et al. Its advantage lies in evaluating and measuring the effectiveness of multiple input and output variables. This article analyzes the financing efficiency using a fixed-scale remuneration CCR model and a variable-scale remuneration BCC model.

\subsubsection{The establishment of the CCR model:}

$$
\left\{\begin{array}{l}
\min \left[\theta-\epsilon\left(\sum_{j=0}^{m} S^{-}+\sum_{j=0}^{n} S^{+}\right)\right] \\
\sum_{j=1}^{n} X j \lambda j+S^{-}=\theta X_{0} \\
\sum_{j=1}^{n} Y j \lambda j+S^{+}=Y_{0} \\
\theta, \lambda j, S^{-}, S^{+} \geq 0
\end{array}\right.
$$

$\theta$ is the coefficient of the input vector for decision unit j, $0<\theta^{0}<1$, non-DEA is valid; if it is $\theta^{0}=1$, DEA is valid.

\subsubsection{The establishment of BBC model:}

After adding the constraint of $\sum \lambda^{*}=1$ on the basis of the CCR model, a purely technically effective BBC model is obtained.

$$
\left\{\begin{array}{l}
\min \left[\theta-\epsilon\left(\sum_{j=1}^{m} S^{-}+\sum_{j=1}^{n} S^{+}\right)\right] \\
\sum_{j=1}^{n} X j \lambda j+S^{-}=\theta X_{0} \\
\sum_{j=1}^{n} Y j \lambda j+S^{+}=Y_{0} \\
\sum_{j=1}^{n} \lambda j=1 \\
\lambda j, S^{-}, S^{+} \geq 0
\end{array}\right.
$$

If $\sum \lambda j^{*}<1$, the DMU decision-making unit will increase the returns to scale. If $\sum \lambda^{*}=1$, the scale returns will be the best. If $\sum \lambda_{j}^{*}>1$, the scale returns will decrease.

\subsection{Sample selection and data sources}

The sample object of this article selects information transmission, software and information technology services, which are the enterprise in the new OTC implementing private placement from January 1, 2017 to December 31, 2017. In order to better study the privatae placement efficiency. The data deletion of the decision unit DMU is as follows:

1. Exclude consecutive loss of business (ST).

2. Only companies that have not been financed in the past year.

3 Some enterprises which miss data and abnormal data.

A total of 328 companies are selected as the decision unit DUM. Considering the accuracy, timeliness, and availability of input and output data, this article selects related financial data of the sample companies for the two-year period of 2016-2017. The data originates from the SME share transmission system website, the Wind database, and Oriental Wealth. network. Some of these data have negative or zero values. Since the DEA model requires non-negative data, this article uses a non-dimensionalized method to process the data and assign it to the interval $[0,1]$. The subsequent data does not change its own meaning and does not have any material impact on the results of the model. The non-dimensionalized variable is expressed as $\mathrm{Y}$ :

$$
\mathrm{Y}=0.1+0.9 \mathrm{x} \frac{\mathrm{X}-\mathrm{Xmin}}{\mathrm{Xmax}-\mathrm{Xmin}}
$$

$\mathrm{X}$ is the original data, $\mathrm{Y}$ is the adjusted data, $\mathrm{Xmin}$ is the minimum value of the variable, and Xmax is the maximum value of the variable. 


\subsection{Model index selection}

The DEA model is a effective evaluating method of a multi-input, multioutput decision-making unit of the same type. On the basis of the influence factors of the financing efficiency of small enterprises, it is analyzed, and it determines the output index and input index.

\subsubsection{Output index}

\subsubsection{Return on equity (ROE)}

It is used to measure the utilization rate of the company's use of free capital in the business process, that is, the percentage of the company's after-tax profit divided by the net assets. The higher the index value is, the better the operational efficiency is.

\subsubsection{Growth rate of main business income (PORIR)}

It is used to reflect the growth of the company's main business, which is the difference between the income from the main business of the reporting period and the income from the main business of the base period divided by the percentage of the income from the main business of the base period. The higher the index is, the better the business operations are.

\subsubsection{Total assets turnover (TATR)}

It is used to reflect the utilization efficiency of assets in production, that is, the operating income which is divided by the average balance of total assets.

\subsubsection{Earnings per share (EPS)}

It is often used to reflect the company's operating results, to measure the level of common stock's profit, and the net profit at the end of the period divided by the total capital at the end of the period.

\subsubsection{Input index}

\subsubsection{Total assets}

It is used to represent the size of the business.

\subsubsection{Asset-liability ratio}

It is used to indicate that the proportion of the company's debt-raised amount to total assets can reflect the rationality of the company's capital structure.

\subsubsection{Concentration of ownership (top ten largest shareholders)}

It refers to the formation of quantitative index for the concentration of shares or the dispersion of shares because of the difference in shareholding of shareholders. It can show the distribution status of the company's equity, and it is also an important index to measure the strength of the company's stability, but also an important index of the company's structure.

\subsubsection{Financial expenses}

This index plays an absolutely important role in financing research, directly influencing main business income, and then reflecting the company's growth ability.

\subsubsection{Operating costs}

Various direct costs which are directly related to the operating income. The operating costs mainly contain main business costs and other business costs.

\subsection{Empirical analysis}

Table 1: DEA financing efficiency values

\begin{tabular}{|c|c|c|c|c|}
\hline Annual & & DEA valid & DEA invalid & $\begin{array}{l}\text { mean value of } \\
\text { efficiency }\end{array}$ \\
\hline \multirow[t]{3}{*}{2016} & $\begin{array}{ll}\text { integrated technology } \\
\text { efficiency } \\
\text { TE }\end{array}$ & $36 \quad(10.98 \%)$ & $292(89.02 \%)$ & 0.951 \\
\hline & $\begin{array}{ll}\text { Pure } & \text { technical } \\
\text { efficiency } & \\
\text { PTE } & \\
\end{array}$ & $42(12.80 \%)$ & $286(87.20 \%)$ & 0.970 \\
\hline & $\begin{array}{l}\text { scale efficiency } \\
\text { SE }\end{array}$ & $38(11.59 \%)$ & $290(88.41 \%)$ & 0.981 \\
\hline \multirow[t]{3}{*}{2017} & $\begin{array}{ll}\text { integrated technology } \\
\text { efficiency } \\
\text { TE }\end{array}$ & $43(13.11 \%)$ & $285(86.89 \%)$ & 0.955 \\
\hline & $\begin{array}{ll}\text { Pure technical } \\
\text { efficiency } \\
\text { PTE }\end{array}$ & $52(15.85 \%)$ & $276(84.15 \%)$ & 0.983 \\
\hline & $\begin{array}{l}\text { scale efficiency } \\
\text { SE }\end{array}$ & $45(13.72 \%)$ & $283(86.28 \%)$ & 0.972 \\
\hline
\end{tabular}

From the perspective of DEA financing efficiency (Table 1 ), the evaluation results of financing efficiency in 2017 show that 43 of the 328-information transmission, software, and information technology service companies have an integrated efficiency value of 1 , and the slack variable of their input and output index is 0 , which accounts for $13.11 \%$ of the total. It is an increase of $2.13 \%$ compared to 2016 . For other enterprises whose financing efficiency is less than 1 , it indicates that there is input redundancy or output shortage, and their input or output needs to be improved.
From the perspective of the average efficiency, the integrated technical efficiency average, pure technical efficiency, and scale efficiency are 0.951 , 0.970 , and 0.981 respectively in 2016. After the private placement in 2017, the average efficiency of the three factors was $0.955,0.9683$, and 0.972 , respectively. Both of the first two factors' values have improved, and the scale efficiency has declined. As a whole, after the sample companies conducted targeted financing in 2017, they had improved their financing efficiency compared to 2016, but their margins were modest and needed further improvement. 
Table 2: Financing Efficiency Level

\begin{tabular}{|c|c|c|c|c|c|}
\hline \multicolumn{2}{|c|}{$\begin{array}{l}\text { Financing } \\
\text { efficiency index }\end{array}$} & $\begin{array}{l}\text { Inefficiency } \\
0<\mathrm{h}<0.5\end{array}$ & $\begin{array}{l}\text { Low efficiency } \\
0.5=<\mathrm{h}<0.8\end{array}$ & $\begin{array}{l}\text { Higher Efficiency } \\
0.8=<\mathrm{h}<1\end{array}$ & $\begin{array}{l}\text { optimum efficiency } \\
\mathrm{h}=1\end{array}$ \\
\hline \multirow{3}{*}{2016} & $\begin{array}{l}\text { integrated } \\
\text { technology } \\
\text { efficiency } \\
\text { TE }\end{array}$ & $\begin{array}{l}0 \\
(0 \%)\end{array}$ & $\begin{array}{l}3 \\
(0.01 \%)\end{array}$ & $\begin{array}{l}289 \\
(88.11 \%)\end{array}$ & $\begin{array}{l}36 \\
(11.88 \%)\end{array}$ \\
\hline & $\begin{array}{l}\text { pure technical } \\
\text { efficiency } \\
\text { PTE }\end{array}$ & $\begin{array}{l}0 \\
(0 \%)\end{array}$ & $\begin{array}{l}1 \\
(0.003 \%)\end{array}$ & $\begin{array}{l}285 \\
(86.89 \%)\end{array}$ & $\begin{array}{l}42 \\
(12.80 \%)\end{array}$ \\
\hline & $\begin{array}{l}\text { scale efficiency } \\
\text { SE }\end{array}$ & $\begin{array}{l}0 \\
(0 \%)\end{array}$ & $2(0.01 \%)$ & $\begin{array}{l}276 \\
(84.15 \%)\end{array}$ & $\begin{array}{l}50 \\
(15.24 \%)\end{array}$ \\
\hline \multirow{3}{*}{2017 年 } & $\begin{array}{l}\text { integrated } \\
\text { technology } \\
\text { efficiency } \\
\text { TE }\end{array}$ & $\begin{array}{l}0 \\
(0 \%)\end{array}$ & $\begin{array}{l}1 \\
(0.003 \%)\end{array}$ & $\begin{array}{l}284 \\
(86.59 \%)\end{array}$ & $\begin{array}{l}43 \\
(13.11 \%)\end{array}$ \\
\hline & $\begin{array}{l}\text { pure technical } \\
\text { efficiency } \\
\text { PTE }\end{array}$ & $\begin{array}{l}0 \\
(0 \%)\end{array}$ & $\begin{array}{l}0 \\
(0 \%)\end{array}$ & $276(84.15 \%)$ & $\begin{array}{l}52 \\
(15.85 \%)\end{array}$ \\
\hline & $\begin{array}{l}\text { scale efficiency } \\
\text { SE }\end{array}$ & $\begin{array}{l}0 \\
(0 \%)\end{array}$ & $\begin{array}{l}1 \\
(0.003 \%)\end{array}$ & $282(85.98 \%)$ & $\begin{array}{l}45 \\
(13.72 \%)\end{array}$ \\
\hline
\end{tabular}

Note: The data is compiled by the calculation results of Deap2.1 software

After calculating the financing efficiency result by Deap2.1, and then classifying the efficiency level according to the efficiency value, from the data collation of Table 2, the enterprise efficiency values of the information transmission, software, and information technology service industries are mainly between $0.8-1$, indicating that the efficiency of the industry in the new OTC market is high, but there are few companies that achieve the best, and the financing efficiency needs to be improved.

In addition, in the sample analysis, most of the companies are in the stage of increasing scale, indicating that the new OTC SMEs are very urgent for financing needs. According to Deap2.1's calculations, there were 11 companies with diminishing returns on scale in 2017, and in 2017 the sample companies' returns on scale declined to 2 only.

\section{CONCLUSIONS AND SUGGESTIONS}

Based on the measurement and analysis of the DEA model, the article studies the efficiency of private placement financing of the information transmission, software, and information technology services industry about new over the counter market and draws the following conclusions:

First, through private placement, the scale and the benefits of the enterprise has been improved, making the original The scale returns to a progressive state with a decreasing state. Second, because of the imperfect market mechanism and blindness in financing, the efficiency of the use of funds by enterprises is not high. This is because of the fact that the purely technical efficiency does not lead to a significant difference in value among companies. Third, from the Deap2.1 operating results, we can draw a large-scale index of the company's scale. After adjustment, the DEA is effective. Therefore, the main factor affecting the financing efficiency is scale efficiency.
For the SMEs in the software and services industry, the following three optimization proposals have been put forward for the low efficiency of financing on the new OTC: First, enhance the capital operation ability of the company and increase the efficiency of fund use. The companies need to optimize their internal management systems and reduce their concentration of ownership. Second, the companies rationally plan their input and output values and increase their economies of scale. Third, improve the market mechanism of the new OTC and expand financing channels. The new OTC should introduce an effective system of change and transmission system as soon as possible. The auction trading system can greatly increase the liquidity and valuation of the new OTC market and increase the efficiency of corporate financing. Fourth, the government should directly use the reasonable tax concessions to alleviate the problem of capital turnover difficulties of the new OTC companies, and it can also attract more investors to invest in the new OTC market.

\section{REFERENCES}

[1] Liang, L., Jinchuan, C. 2003. DEA Method Input and Output Project Selection and Data Processing [J]. Journal of Systems Engineering, (6), 487490.

[2] Chongrun, W., Zan, W. 2016. new over the counter Listed Companies Financing Efficiency Analysis [J]. Shanghai Finance, (11), 70-75.

[3] Xiaoning, W., Turin, Qibiao, W. 2016. Analysis of SME Financing Efficiency Based on Three-phase DEA Model [J]. Statistics and Decision, (05), 179-182.

[4] Mishikin, Frederic, S. 1999. Financial Consolidation: Dangers and Opportunities. Journal of Banking \& Finance, 23. 